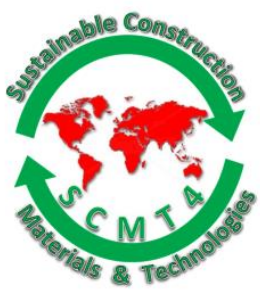

\title{
Electrochemical Performance of Organic Zinc-Rich Coating as an Impressed Current Anode System
}

\author{
Homayoon Sadeghi-Pouya ${ }^{1}$, Eshmaiel Ganjian $^{2}$, and Omid Golshadi ${ }^{3}$ \\ ${ }^{I}$ Research Fellow, Department of Civil, Architecture and Building, Faculty of Engineering \& Computing, \\ Coventry University, CV1 5FB, Email: <H.Sadeghipouya@coventry.ac.uk〉, Senior Materials Engineer, \\ Atkins, The Axis, Birmingham, UK, B1 1 TF, Email: <Homayoon.Sadeghipouya@atkinsglobal.com>. \\ ${ }^{2}$ Professor of Civil Engineering Materials, Department of Civil, Architecture and Building, Faculty of \\ Engineering \& Computing, Coventry University, UK, CV1 5FB, Email: 〈E.Ganjian@Coventry.ac.uk〉. \\ ${ }^{3}$ MSc student in Civil, Architecture and Building Department, Coventry University, UK, CV1 5FB, \\ Email: <omid.golshadi@yahoo.com>.
}

\begin{abstract}
Cathodic protection is a proven technique to halt or minimise corrosion of steel embedded in concrete structures and bridges exposed to chloride from road dicing salt. Cathodic protection for reinforced concrete has generally been limited to impressed current systems due to the relatively high resistivity of concrete and reduced life of galvanic zinc anodes at high chloride content. Zinc rich paints (ZRP) are widely used as an anti-corrosion paint on steel substrates, an alternative to hot-dip galvanising. A type of vapour-permeable zinc-rich paint made of $96 \%$ zinc has been proposed for cost effective and low maintenance impressed current cathodic protection of reinforced concrete structures. To evaluate its potential application in practice, the electrical, and electrochemical properties of the material have been investigated. The zinc-rich anode was found to shift the potential of the steel to more negative potentials successfully and satisfy the performance criteria in accordance with BS EN ISO 12696. In this research it is found that the optimum conductivity will be achieved by three coats to produce $280-320 \mu \mathrm{m}$ thickness in order to get a good current distribution in the surface of the anode.
\end{abstract}

\section{INTRODUCTION}

One of the most commonly used materials in structures is reinforced concrete. It has many different uses, is economical and abundantly available. In addition, it could be shaped to a different mould. Reinforced concrete is known as strong, staying in good condition for a long time even if used a lot, and its performance through its service life is quite good. However, in some cases reinforced concrete does not have a sufficient performance because of bad quality, poor construction, placed near marine environment, or combination of those factors. There is a big problem of the reinforced steel in concrete, which is 'corrosion'. Globally, concrete is used more than other artificial material in construction (Broomfield, 2007).

Cathodic protection is an electrochemical method to reduce or stop corrosion by providing current from an external source to suppress the current flow in order to reduce process of corrosion of reinforced bars. The 
external current source can be transferred by combination of steel to another metal that should be active such as zinc. According to the USA Federal Highway Administration, the usage of cathodic protection has been proved as the only rehabilitation technique in order to reduce or stop the rate of corrosion, especially for concrete that is contaminated by chloride (Anwar et al, 2014 and Barnhart, 1982). In addition, by using this method of protection about $\$ 50$ billion can be saved for cost of repairs in 30 years (Federal Highways Administration, 1991). According to Das (2012) the most vital factor for a successful cathodic protection system is the design of an effective anode system in order to dispense the essential protection current. Since the first cathodic protection system has been installed on a concrete bridge in California, in the US, many other anode systems, and anode materials have been considered. However, all anode systems are not proved as an effective or appropriate for any kind of structures.

Impressed current system. Impressed current cathodic protection has been used as a good technique for reinforced concrete in order to stop or reduce corrosion rate since 1970 (Chess, 2007 and Oladis et al, 2008). Impressed current cathodic protection system was used in California, in the US, involved anode material in roadway bridge decks. At that time the original anode material was conductive carbon which was applied on overlays of asphalt. Then anode materials have been developed by other materials like resin and other polymers, niobium coated, and copper cored wires (primary anodes). Impressed current cathodic protection is usually known as a relevant and suitable technique in order to mitigate the corrosion rate for reinforced concrete. In addition, for those structures that they are buried or submerged SACP (sacrificial anode cathodic protection) could be effective. Practically, most impressed cathodic protection systems have been used in bridges, buildings, and marine environment, which they are located in above ground structures.

\section{The advantages of impressed current cathodic protection}

- It should be effective between 20 and 50 years or more if there is a suitable maintenance.

- The life time of anodes have been proven to be between 20 and 50 years by technology.

- There are some standards for operation and installation (Broomfield, 2007).

\section{The disadvantages of impressed current cathodic protection}

- It will need power supply permanently.

- It will require monitoring and maintenance regularly.

- Constant power supply would be needed (Broomfield, 2007).

Primary anodes. In most impressed current cathodic protection systems for reinforced concrete are required by primary anodes (Chess, 2007).

Zinc Rich Paints. Zinc rich paints are generally used as a paint of anti-corrosion on substrates of ferries in order to protect the steel and structures are placed near marine environment. The content of metallic zinc is very vital parameter in the dry films due to emphasise in the specifications of technical of zinc rich paints. On the other hand, this factor is not just the only parameter that determines the performance of this paint. For instance, particle size of zinc and chemical nature of binder are also important. The dust of zinc is in a round shape and has been dispersed in an organic, usually organic binder.

Generally zinc has been intruded as pigments of spherical and has got a diameter between 5 and $10 \mu \mathrm{m}$. Pigments will be needed with high concentration with more than $60 \%$ of volume in solvent based zinc rich paints in order to have a good contact between pigments of zinc and substrate of steel.

\section{Advantages of zinc}

- Coating of zinc rich paint has got a sufficient adhesion to a concrete substrate. When the current has been applied for forty days, the strength value is risen between the concrete and zinc rich paint. 
The chemical reaction between cement and zinc rich paint has been affected to increase in bond strength.

- Results have been shown that the zinc rich paint coating is capable of supporting high level of current.

- According to NACE standard TM0294, the service life of the zinc rich paint by applying current density of $10 \mathrm{~mA} / \mathrm{m}^{2}$ should work well for more than 20 years. On the other hand, the service life of coating of zinc rich paint or thermally sprayed zinc have been depended by the reaction of electrochemical at the zinc coating concrete interface.

- There is a little difference of potential of polarisation with distance from the primary anodes which is shown by electrochemical test (Das, 2015).

\section{Disadvantage of zinc}

- When the zinc is coupled to the steel it has a small driving voltage, therefore it will not be adequate to provide full protection especially in very high chloride conditions.

Components of cathodic protection system. Basically, cathodic protection system includes a conductor which is called anode. Anode delivers a small direct current flow through the reinforced concrete that is shown in figure 1 . The potential of steel will becoming negatively and the corrosion would be stopped. Anode could be placed to the surface of concrete like conductive coating or can be either consisted of a mesh of activated titanium or carbon fibre which are embedded in a cementitious overlay. The other types of anode consists titanium strips in boreholes with cementitious mortar. In addition, the anode system will be linked through anode copper connections and has been isolated copper cables to the power supply. Furthermore, one of the other components of cathodic protection system is called reference electrode. Reference electrodes are embedded to the concrete and are used for controlling protection and a low voltage power source. In order to make sure that cathodic protection is working correctly which will be needed routine monitoring that is carried out by depolarisation (electrical measurements) two times a year at least. In addition, visual inspection will be needed once a year (BS EN, 2012).

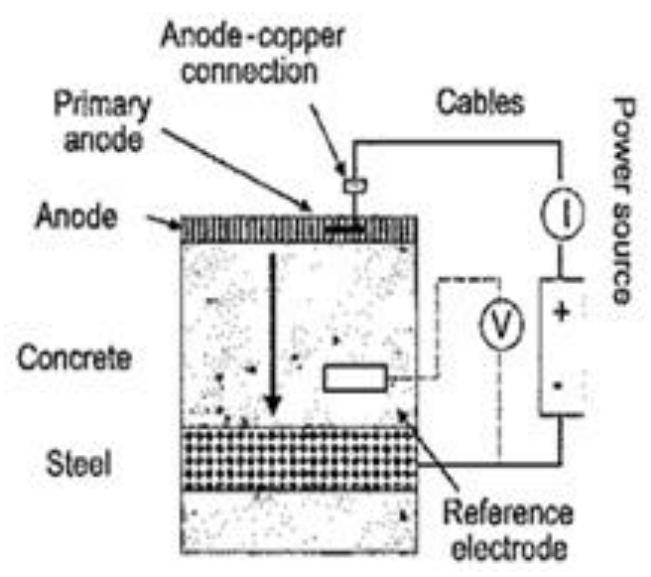

Figure 1. Basic setup of a concrete cathodic protection system (Podler et al, 2014)

\section{EXPERIMENTAL PROGRAM}

Preparation of specimens. 9 concrete slab specimens with $200 \times 200 \times 70 \mathrm{~mm}$ were made using a single mix design for C35 grade concrete. The water to cement ratio for all samples was 0.5 , and all concrete casting were carried out in accordance with BS 1881-125: 2013. Two mild steel bars with the diameter of $10 \mathrm{~mm}$ with minimum $50 \mathrm{~mm}$ cover were included in the concrete specimens. For monitoring purpose one silver /silver chloride and one MMO/Ti reference electrodes were embedded in concrete. The steel bars 
have been covered with sleeve in order to prevent corrosion of expose portion of them and electrical connections in salt solution. All connections made outside of the concrete samples were encapsulated with heat shrink sleeve. $3 \%$ sodium chloride per weight of cement has been added deliberately to the mix design of concrete in order to accelerate corrosion. Figure 1 shows the arrangement of various components in concrete specimens.

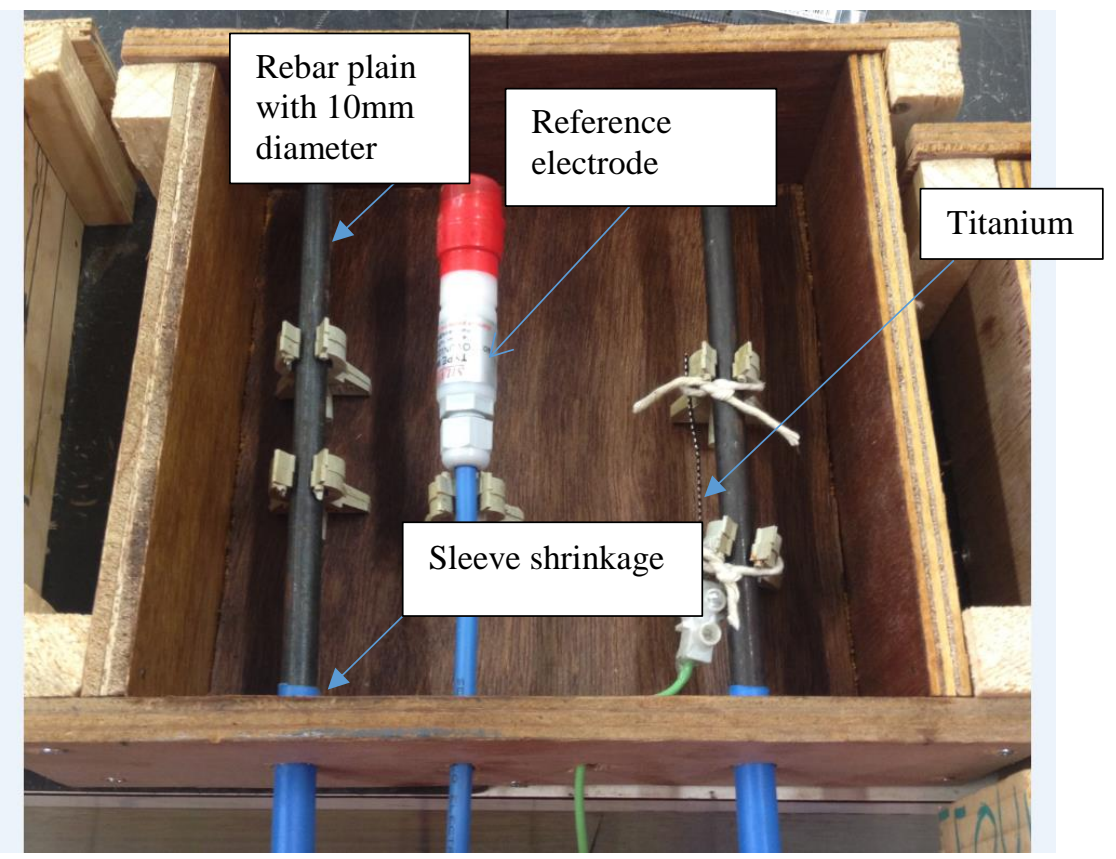

Figure 2. Components of test specimens

All specimens were demoulded 24 hours after casting, then they were transferred to the tank of potable water with the temperature of $20^{\circ} \mathrm{C} \pm 2{ }^{\circ} \mathrm{C}$ for curing. The curing was applied for 4 days in temperature of $20^{\circ} \mathrm{C} \pm 2{ }^{\circ} \mathrm{C}$. After curing all samples were transferred to a corrosion tank containing $3 \%$ sodium chloride salt solution at $20^{\circ} \mathrm{C} \pm 2{ }^{\circ} \mathrm{C}$ temperature.

Preparation of surface. Before coating the surface of concrete with anode paint, the dust and laitance at the surface were removed with a wire brush and surface was roughen with aggregates slightly exposed to achieve an effective bond between zinc and concrete.

Application of zinc rich paint anode. Each sample has been applied by three coats of zinc rich paint with a new brush paint in order to achieve approximate thickness $300 \mu \mathrm{m}$. Three coats have been applied in accordance with the manufacture's recommendations for waiting time between each coat. For health and safety reason, zinc has been applied in the open-air.

\section{Measurements}

1. The natural potential between every bar and reference electrode were measured regularly prior to application of ICCP.

2. Zinc rich paint anode was connected to the positive terminal of the power supply in order to provide constant current and the following parameters were measured: 
- the as-found voltage

- The applied current

- Potential of reference electrode

- Check the resistance of connections:

○ The resistance for all connections was measured with multi-meter and was confirmed to be less than $1 \mathrm{O} \mathrm{hm}$.

Setup of test. After preparation of samples, they were placed in the $3 \%$ chloride solution (Figure 2). The potential between cathode and reference electrode was measured by multi-metre and the potential readings were recorded. When the potential was stable, so the specimen can be connected the power supply in order to apply cathodic protection and meet the criteria recommended by BS EN 12696: 2012. The next step was to monitor the polarization of the steel bars as the current was delivered by ZRP anode in impressed current cathodic protection (ICCP). $0.1 \mathrm{~mA}, 100 \mathrm{~mA}, 200 \mathrm{~mA}$ current outputs were applied at the power supply as a constant current and maintained until the polarised potential of steel bars became stable. The current outputs applied were equivalent to current densities 10,68 and $135 \mathrm{~mA} / \mathrm{m} 2$ with respect to steel surface area and 2.5, 2500 and $5000 \mathrm{~mA} / \mathrm{m} 2$ with respect to ZRP anode surface area. This required about 10 days for the concrete specimens tested. During the polarization test it was necessary to record it every two hours to capture any interim changes in the potential of reference electrodes. After 10 days when polarization remained stable, the power supply was switched off then the instant off reading was taken in 1 second. This process was continued for twenty four hours and the depolarisation interval was recorded in order to obtain the potential decay of steel bars in concrete.

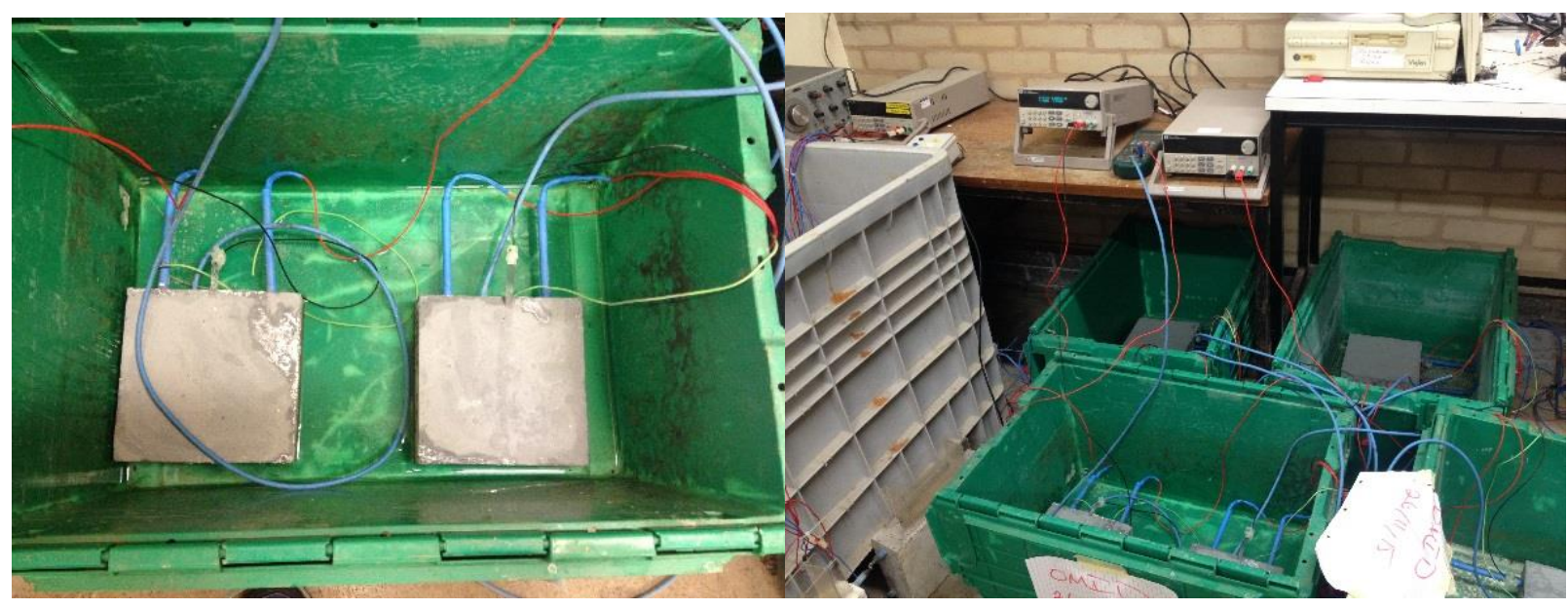

Figure 3. Arrangement of the test rig

\section{RESULTS AND DISCUSSION}

The potential between the cathodes and reference electrode of the 9 samples which were monitored and measured for 10 days before connection to the power supply and application of ICCP. The measured natural potential of steel bars with respect to silver/silver chloride reference electrode is shown in table 1.

The range of active corrosion for potential of half-cell of steel in concrete is less than $-200 \mathrm{mV}$ and more negative than -350 which represent $\% 10$ and $\% 90$ chance of corrosion happening at the time which is being measured (ASTM C 876-91). If the corrosion potential is more negative than $-350 \mathrm{mV}$ that means, there is a high risk of corrosion in the sample. On the other hand, if the potential is more positive than $-200 \mathrm{mV}$ that means the probability of corrosion of steel in concrete is low. 
Table 1. Average reference electrode potentials in samples containing chloride

\begin{tabular}{|c|c|c|}
\hline Days & $\begin{array}{c}\text { Average potential between } \\
\text { rebar (mV) and reference } \\
\text { electrode } \\
\text { Sample with no chloride } \\
\text { added (Das, 2012) }\end{array}$ & $\begin{array}{c}\text { Average potential between } \\
\text { rebar (mV) and reference } \\
\text { electrode } \\
\text { Sample with 3\% chloride } \\
\text { added }\end{array}$ \\
\hline 1 & -144 & -278 \\
\hline 2 & -152 & -318 \\
\hline 3 & 169 & -321 \\
\hline 4 & -171 & -326 \\
\hline 5 & -170 & -330 \\
\hline 6 & -175 & -333 \\
\hline 7 & -183 & -331 \\
\hline 8 & -178 & -339 \\
\hline 9 & -180 & -339 \\
\hline 10 & -205 & -340 \\
\hline
\end{tabular}

As discussed earlier, all samples were added 3\% sodium chloride deliberately in order to accelerate the potential of corrosion. It was noted that all reference electrode potentials were more negative than $-200 \mathrm{mV}$ confirming active state of corrosion. The reading taken from specimens with 3\% chloride ranged between -278 and $-340 \mathrm{mV}$. The reading was also compared to corrosion potential from control samples (Das, 20102) that did not contain any added chloride in the concrete mix; however, they were placed in a tank which contained 3\% chloride. The control samples also showed a slight sign of risk of corrosion due to exposure to an external source of chloride i.e., salt solution. Chloride could be transferred to the concrete through the pores within the sample of concrete. The potential readings which were taken between rebar 1 and reference electrode and rebar 2 and reference electrode for all samples including chloride contained and control samples were found to be in the same range.

Result of polarisation. Specimens with ZRP anode were connected to power supply in order to provide impressed current cathodic protection. The polarised potential of steel polarization recorded in 10 days with various current outputs. The result of polarization showed that by increasing the voltage the potential dropped down (i.e. became more negative). According to equation $V=R I$ by increasing the voltage the current should be risen. Although the resistance between the concrete and anode ranged between 2 and $6 \mathrm{M}$ $\mathrm{Ohm}$, the power supply was able to deliver the required current to the sample in order to polarise the steel. It should be noted when the power supply switches on and the current is delivered through the paint anode system, the corrosion should supressed and the polarised potential should be shifted negatively. In the sample which was coated by zinc, the steel was polarised almost immediately after application of cathodic protection current. It was noted that zinc rich paint has adequate electrical conductivity and was able to polarise the steel efficiently. After ten days the polarised potential in samples with ZRP became stable with no significant change suggesting that the performance criteria of BS EN 12696:2012 can be met. This will be in depolarisation section. Figures 4 to 6 show the change in potential of steel after application of ICCP and during 10 days polarisation. 


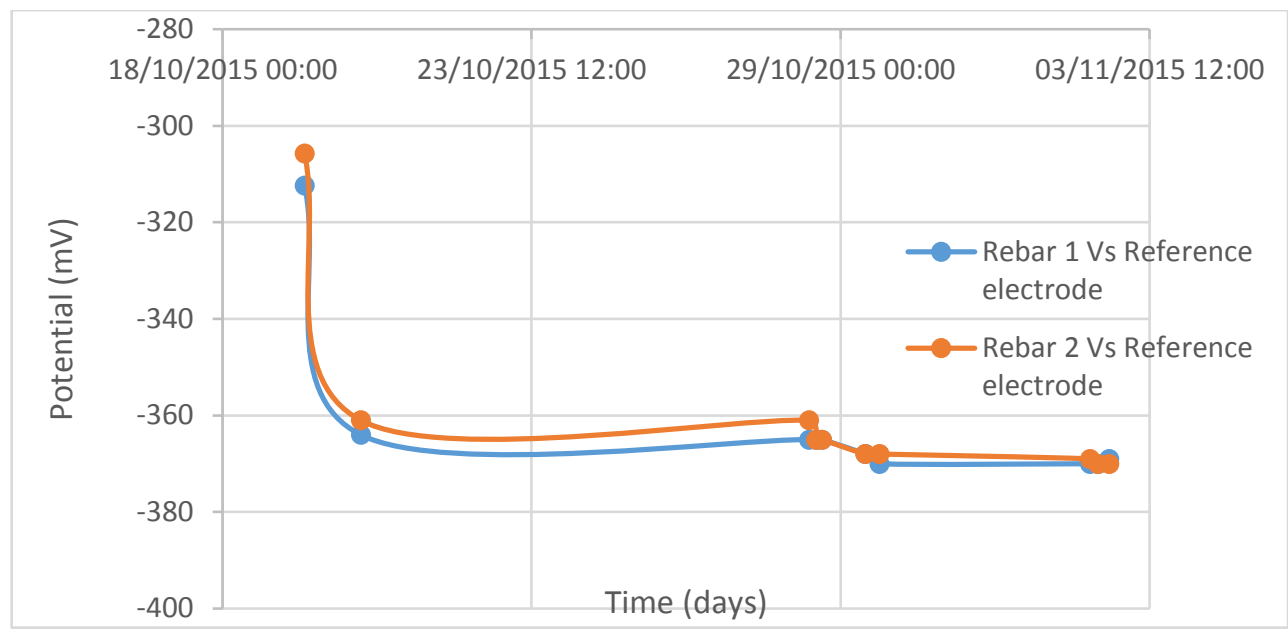

Figure 4. Reference electrode potential for samples (current density $2.5 \mathrm{~mA} / \mathrm{m} 2$ with respect to zinc surface area)

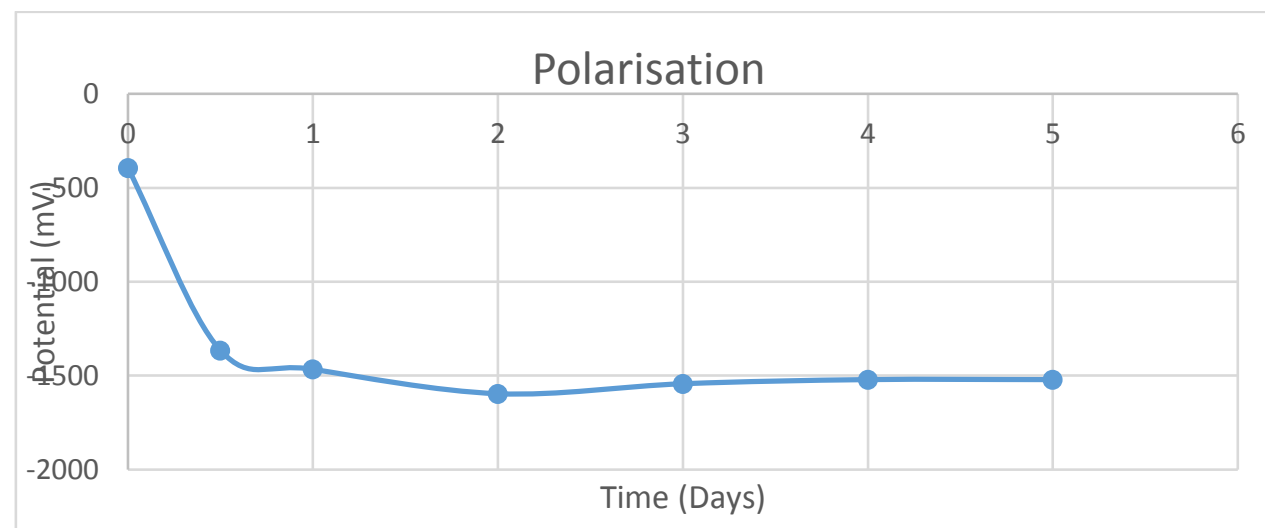

Figure 5. potential between silver/silver chloride reference electrode and cathodes for samples (current density $2500 \mathrm{~mA} / \mathrm{m} 2$ with respect to zinc surface area)

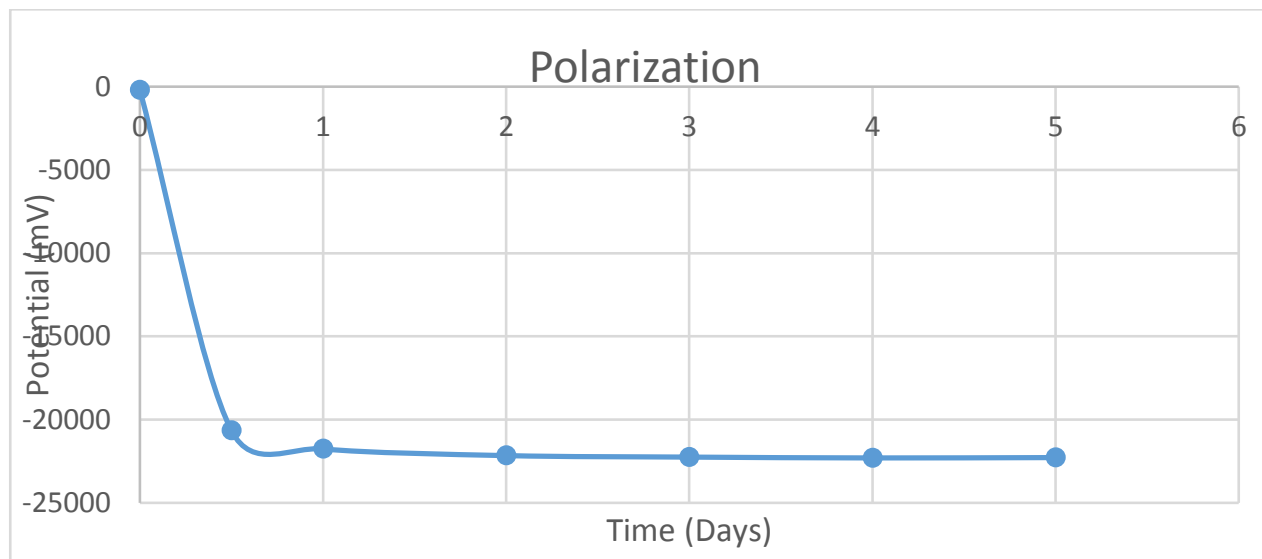

Figure 6. potential between silver/silver chloride reference electrode and cathodes for samples (current density $5000 \mathrm{~mA} / \mathrm{m} 2$ with respect to zinc surface area) 


\section{Results of Depolarisation}

The results of depolarisation are shown in figures 7 to 9 . When the power supply was switched off the instant off was taken immediately between 0.1 and 1 seconds, then the readings of depolarisation have been taken. According to BS EN ISO 12696: 2012, cathodic protection of steel in concrete the readings of depolarisation could be taken at 1, 2, 4,8 and 24 hours. In order to meet the performance criteria, the potential decay should be at least $100-150 \mathrm{mV}$ during 24 hours after the depolarisation started. It should be noted that all samples contaminated with $3 \%$ chloride satisfied the $100 \mathrm{mV}$ decay criterion of BS EN ISO 12696:2012.

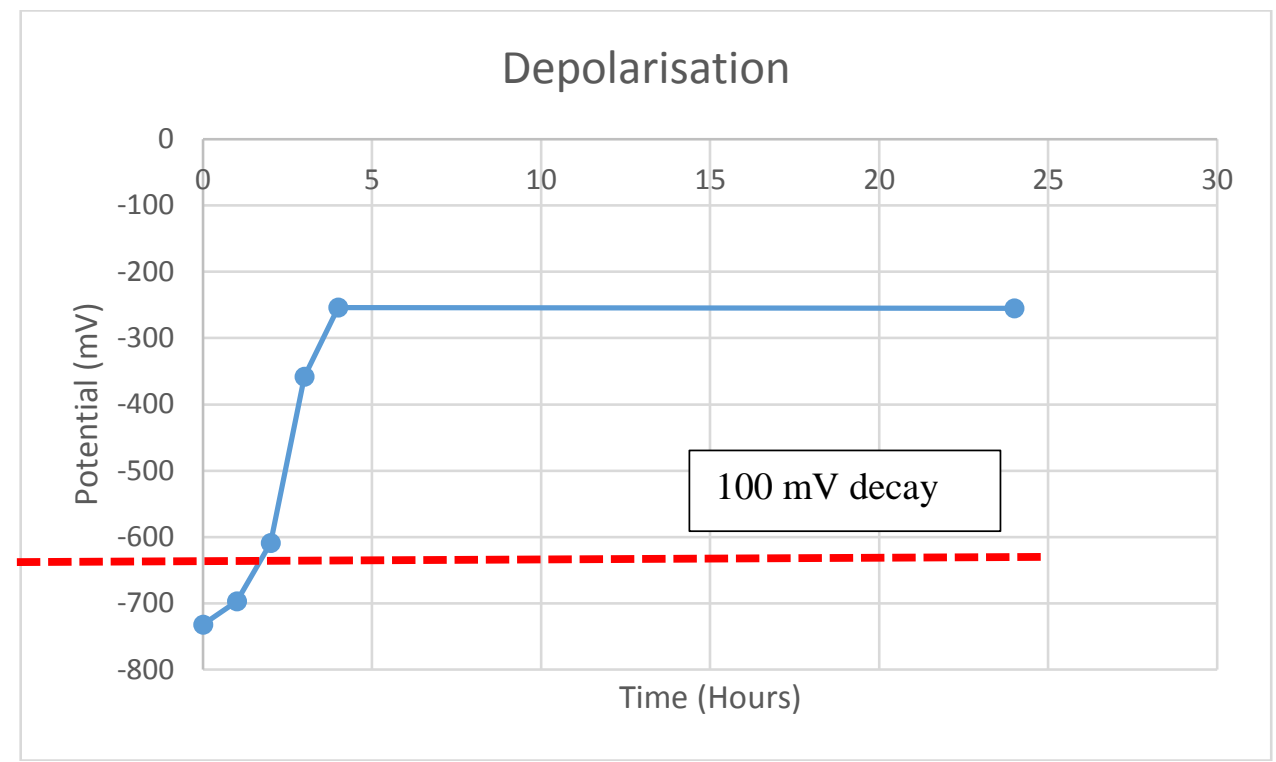

Figure 7. Readings of depolarisation of sample $s$ (current density $2.5 \mathrm{~mA} / \mathrm{m}^{2}$ with respect to zinc anode surface area)

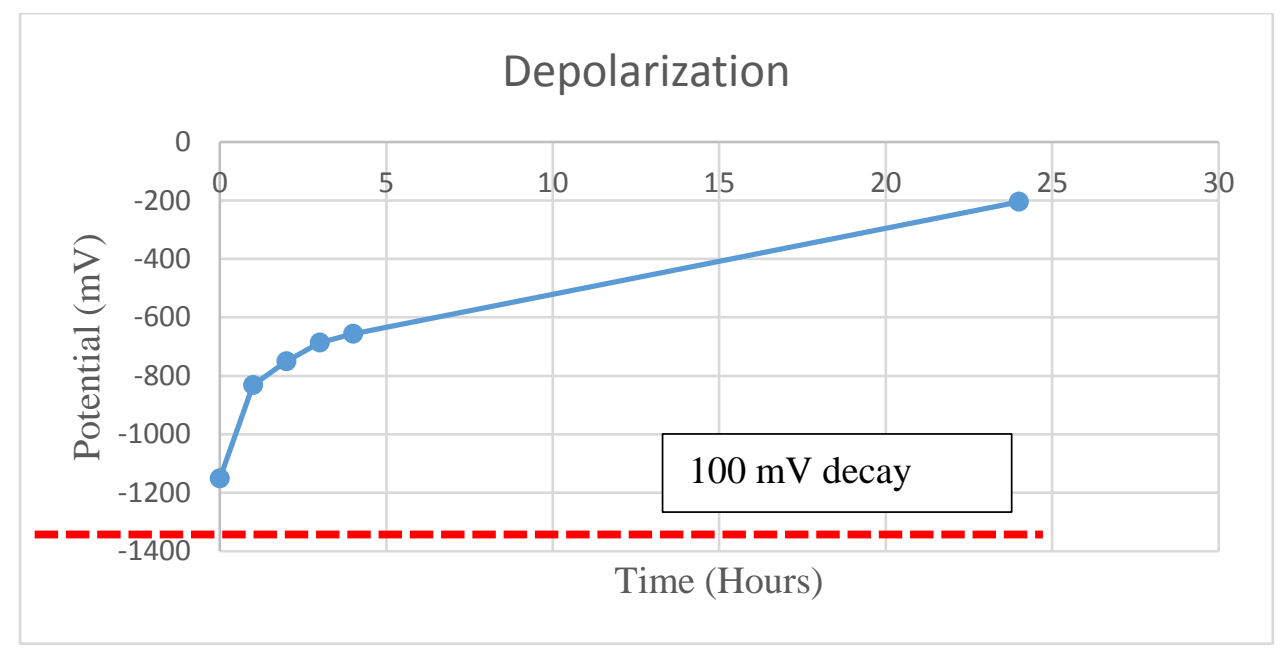

Figure 8. readings of depolarisation of samples (current density $2500 \mathrm{~mA} / \mathrm{m}^{2}$ with respect to zinc anode surface area) 


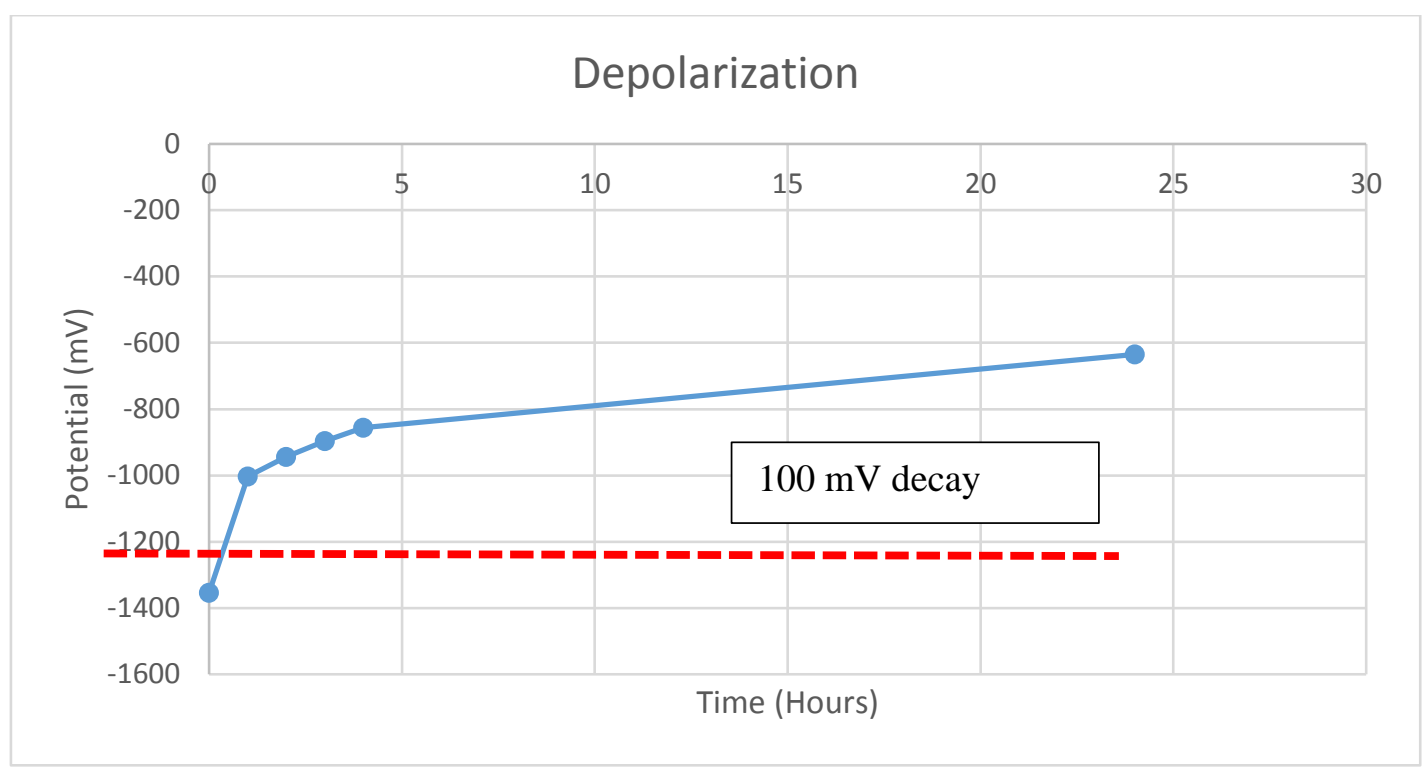

Figure 9. readings of depolarisation of samples (current density $5000 \mathrm{~mA} / \mathrm{m}^{2}$ with respect to zinc anode surface area)

Depolarisation is one of the well accepted criterion that indicates level of protection of steel by cathodic protection. According to Das (2012), if the decay for four hours is $100 \mathrm{mV}$ or more than that, it means the system is working correctly. To achieve full and optimum protection of steel according to BS EN ISO 12696:2012, the instantaneous off which is the start point of the graphs needs to be either more negative than $-720 \mathrm{mV}$ or from instantaneous off, the potential decay over 24hours to be at least more than $100 \mathrm{mV}$. The results presented above confirmed that the performance criteria were met. Results showed that zinc rich paint was capable of delivering and sustaining cathodic protection current at both low and high current densities. Although the long term durability of the ZRP as an anode is still being investigated by the authors, the initial result suggested that the reasonable service life may be achieved.

\section{CONCLUSION}

- Zinc rich paint has adequate electrical conductivity, when is applied in three coats. The resistance between anode and cathode was found to be relatively high; however, it was able to deliver the required current through the zinc-concrete interface.

- The results showed that zinc rich paint can be used as an anode system and was able to sustain low and high level of current density up to $5000 \mathrm{~mA} / \mathrm{m} 2$ with respect to anode surface area.

- Result showed that the zinc rich paint was able to polarise the steel adequately when used for ICCP and satisfy BS EN 12696 performance criteria.

\section{REFERENCES}

Anwar, Mohammad Syaiful, Sujitha, B., Vedalakshmi, R. (2014) 'Light-Weight Cementitious Conductive Anode for Impressed Current Cathodic Protection of Steel Reinforced Concrete Application.'. Full 71, $167-170$ 
Barnhart RA. FHWA position on cathodic protection systems. Memorandum from federal highway administrator to regional and federal programs administrators, April 23, 1982.

Broomfield, J. (2007) Corrosion of Steel in Concrete. Second edn. USA and Canada: Taylor \& Francis

BS EN ISO 12696 (2012) Cathodic protection of steel in concrete, British Standards Institution, London, UK.

Chess, Paul. Gronvold, Karnov. (ed.) (1998) Cathodic Protection of Steel in Concrete. New York: Routledge

NACE (2001) Testing of Embeddable Impressed Current Anodes for use in Cathodic Protection of Atmospherically Exposed Steel- Reinforced Concrete [green/white paper] USA: NACE (21225)

Oladis TR, Yolanda HL, Angelica VM, Anders ATA, Barrios F, Montero P, et al. Environmental influence on point anodes performance in reinforced concrete. Constr Build Master 2008;22(4):494503.

Rob B., Polder., Greet Leegwater., Daniel., Worm., Wim., Courage. (2014) 'Service Life and Cycle Cost Modelling of Cathodic Protection Systems for Concrete Structures'. 47, 69-70

Sunil Chandra Das (2012) Zinc Rich Paint as Anode System for Cathodic Protection (CP) of Reinforced Concrete Structures and Development of corrosion/CP Monitoring Probes. [online] PhD thesis or dissertation. Coventry: Coventry University 